\title{
Competitive Healing of Creep-Induced Damage in a Ternary Fe-3Au-4W Alloy
}

\author{
Y. FU, C. KWAKERNAAK, W.G. SLOOF, F.D. TICHELAAR, E. BRÜCK, S. VAN \\ DER ZWAAG, and N.H. VAN DIJK
}

\begin{abstract}
Autonomous healing of creep-induced grain boundary cavities by Au-rich and W-rich precipitates was studied in a $\mathrm{Fe}-3 \mathrm{Au}-4 \mathrm{~W}$ (wt pct) alloy at a fixed temperature of $823 \mathrm{~K}$ $\left(550{ }^{\circ} \mathrm{C}\right)$ with different applied stresses. The ternary alloy, with two supersaturated healing solutes, serves as a model system to study the interplay between two separate healing agents. The creep properties are evaluated and compared with those of the previously studied $\mathrm{Fe}-\mathrm{Au}$ and Fe-W binary systems. The microstructures of the creep-failed samples are studied by electron microscopy to investigate the cavity filling behavior and the mass transfer of supersaturated solute to the defect sites. Compared to the Fe-Au and Fe-W alloys, the new $\mathrm{Fe}-\mathrm{Au}-\mathrm{W}$ alloy has the lowest steady-state strain rate and the longest lifetime. The site-selective filling of the creep-induced cavities is attributed to two different categories of precipitates: micron-sized Au-rich precipitates and nano-sized W-rich precipitates. The Au-rich precipitates are found capable to fully heal the cavities, while the W-rich precipitates show only a limited degree of healing. The two types of precipitates show a reluctance to coexistence, and the formation of W-rich precipitates is suppressed strongly. A model is proposed to describe the competitive healing behavior of the Au-rich and W-rich precipitates.
\end{abstract}

https://doi.org/10.1007/s11661-020-05862-6

(C) The Author(s) 2020

\section{INTRODUCTION}

WHEN metals are exposed to an elevated temperature $\left(T>0.4 T_{\text {melt }}\right)$, the application of a constant stress generally causes a time-dependent increase in strain. This phenomenon is known as creep. During creep, quasi-spherical micron-sized cavities form preferentially

Y. FU is with the Fundamental Aspects of Materials and Energy group, Faculty of Applied Sciences, Delft University of Technology, Mekelweg 15, 2629 JB and also with the Novel Aerospace Materials Group, Faculty of Aerospace Engineering, Delft University of Technology, Kluyverweg 1, 2629 HS, Delft, The Netherlands. Contact e-mail: Y.Fu-1@tudelft.nl. C. KWAKERNAAK and W. G. SLOOF are with the Department of Materials Science and Engineering, Delft University of Technology, Mekelweg 2, 2628 CD, Delft, The Netherlands. F. D. TICHELAAR is with the Kavli Institute of Nanoscience, National Centre for HREM, Delft University of Technology, Lorentzweg 1, 2628 CJ, Delft, The Netherlands. E. Br̈uck is with the Fundamental Aspects of Materials and Energy group, Faculty of Applied Sciences, Delft University of Technology, Mekelweg 15, 2629 JB, Delft, The Netherlands. S. van der ZWAAG si with the Novel Aerospace Materials Group, Faculty of Aerospace Engineering, Delft University of Technology, Kluyverweg 1, 2629 HS, Delft, The Netherlands and also with the School of Materials Science and Engineering, Tsinghua University, Beijing 100084, China. N. H. van DIJK is with the Fundamental Aspects of Materials and Energy group, Faculty of Applied Sciences, Delft University of Technology, Mekelweg 15, 2629 JB, Delft, The Netherlands.

Manuscript submitted January 7, 2020.

Article published online June 14, 2020 at the grain boundaries oriented perpendicular to the load direction. When these cavities are formed, they grow and coalesce into micro- and subsequently macro-cracks, which ultimately leads to failure. Traditionally, efforts have been made to improve the creep resistance by stabilizing the microstructure of the material and postpone the cavity propagation as long as possible. ${ }^{[1-3]}$ As cavity nucleation is assumed to be inevitable, the concept of self-healing ${ }^{[4-6]}$ is proposed as an alternative strategy, in which the occurrence of the cavities triggers dissolved (non-majority) atoms to move towards the defects and fill them. In this self-healing approach the cavity growth can be interrupted before coalescence takes place.

The idea of self-healing has been applied to various (industrial and model) metallic systems to improve the creep resistance. Lumley et al..$^{[7,8]}$ demonstrated that underaged $\mathrm{Al}$ alloys showed a lower strain rate, and thus a longer lifetime, compared to a fully aged counterparts. The improvement in the creep performance after an under-ageing heat treatment is achieved by the dynamic precipitation of free solute atoms and the subsequent retardation of dislocation motion during the creep test. Laha et al. ${ }^{[9,10]}$ reported that the combined addition of boron and nitrogen into austenitic stainless steels (with an $f c c$ lattice structure) is effective in reducing the cavity growth rate, as well as increasing the creep rupture strength. During creep, BN preferentially precipitates on 
the free cavity surfaces and thereby partially heals the cavities. ${ }^{[9-11]}$ For ferritic steels (with a bcc lattice structure), a series of binary systems, ${ }^{[6,12-20]}$ including $\mathrm{Fe}-\mathrm{Cu}, \mathrm{Fe}-\mathrm{Au}, \mathrm{Fe}-\mathrm{Mo}$ and Fe-W, serving as model alloy systems have been investigated systematically to reveal the mechanism and criteria of self-healing. The composition of these alloys was selected such that at the operating temperatures the solute is in a supersaturated state by approximately 1 at.pct. The supersaturated solute atoms are expected to segregate at the open-volume defect sites and fill them progressively, and therefore, the coalescing of the cavities can be prevented or delayed. The $\mathrm{Fe}-\mathrm{Cu}$ system has been shown to be moderately effective in enhancing the creep resistance. ${ }^{[12,}$ 21] $\mathrm{Cu}$-rich precipitates were found to fill the cavities formed during creep. However, owing to the similar atomic radius of the precipitating $\mathrm{Cu}$ atom and the matrix $\mathrm{Fe}$ atom, the $\mathrm{Cu}$ atoms were found to show only a weak preference to precipitate in the open-volume cavities, in comparison with precipitation along the intact grain boundaries and dislocations within the matrix. ${ }^{[12,13]}$ This competing precipitation route leads to a gradual depletion of the available healing atoms (in the form of supersaturated solute $\mathrm{Cu}$ ) when a cavity is formed and needs to be filled. The $\mathrm{Au}$ atom has an atomic radius that is 13 pct larger than that of the $\mathrm{Fe}$ atom, which results in an appreciable strain energy for segregation in the $\mathrm{Fe}-\mathrm{Au}$ solid solution. It is therefore expected to show an obvious site-selective healing effect, i.e., the Au-rich precipitates will form almost exclusively on the free cavity surface and disk-shaped precipitates connected to the dislocations in the matrix will remain nano-sized as they are restricted in their growth. ${ }^{[14,15,17,20]}$ In a related recent study, Zhang et al. ${ }^{[22]}$ demonstrated that $\mathrm{Au}$ atoms dissolved in bcc iron can also actively heal nuclear radiation damage in a mechanism not unlike that for creep damage healing. Considering the costliness and the limited availability of $\mathrm{Au}, \mathrm{Fe}-\mathrm{Mo}^{[16]}$ and $\mathrm{Fe}-\mathrm{W}^{[18]}$ systems were investigated as an alternative. In Fe-Mo and Fe-W alloys the precipitating phase responsible for healing is not the soluterich $f c c$ phase, but the intermetallic Laves phase $\left(\mathrm{Fe}_{2} \mathrm{Mo}\right.$ and $\mathrm{Fe}_{2} \mathrm{~W}$, respectively). Both the Fe-Mo and $\mathrm{Fe}-\mathrm{W}$ system showed a high self-healing potential and site-selective phenomena similar to the Fe-Au system, except for the slower kinetics due to the lower diffusivity of Mo and $\mathrm{W}$ in bcc Fe. Based on the observations from the above-mentioned experiments and complementary computation studies, ${ }^{[23]}$ the essential requirements for the self-healing capability can be formulated ${ }^{[6]}$ : (i) a supersaturation to provide the driving force so that the healing agent can precipitate at the defect sites; (ii) a relatively large misfit between the matrix phase and the newly formed precipitate phase such that the precipitation within the matrix can be restrained by the nucleation barrier; (iii) a larger diffusivity of the healing element compared to the diffusivity of iron, so that the vacancy flux would be reversed away from the cavity due to the Kirkendall effect; and (iv) there should be no chemical reaction between the healing element and iron matrix so that the solute diffusion towards the cavity is not interfered.
So far, the self-healing of creep damage in ferritic Fe-based alloys by precipitation triggered by cavities ${ }^{[19]}$ resulting in an extended creep lifetime, ${ }^{[1]}$ has only been demonstrated for binary alloys. To transfer the concept of self-healing to systems with a higher complexity closer to that of commercial (multi-component) creep-resistant steels, a ternary Fe-X-Y system with two healing elements can provide insight in the interplay between two separate healing agents in the same system.

In the present study, we explore the damage behavior of a ternary $\mathrm{Fe}-3 \mathrm{Au}-4 \mathrm{~W}$ (wt pct) alloy containing two different healing elements: the fast diffusing $\mathrm{Au}$ and the slower diffusing $\mathrm{W}$. The composition of the alloy was selected such that at the pre-defined and set testing temperature of $823 \mathrm{~K}\left(550^{\circ} \mathrm{C}\right)$ both elements are in a supersaturated state with approximately 1 at. pct of supersaturation for both elements. The concentration of each solute element in the Fe-3Au-4W ternary system is comparable to our previously studied $\mathrm{Fe}-3 \mathrm{Au}$ and Fe-4W binary systems. Creep tests at a fixed temperature with different constant applied stresses were performed to evaluate the creep properties of the new ternary alloy. The resulting microstructures of the fractured samples are studied in detail by scanning and transmission electron microscopy to evaluate the cavity filling behavior and the mass transfer of supersaturated solute to the defect sites.

\section{EXPERIMENTAL}

High-purity $\mathrm{Fe}-\mathrm{Au}-\mathrm{W}$ ternary alloy sheets were produced on order by Goodfellow ${ }^{\circledR}$. The as-received material contains $3.826 \mathrm{wt}$ pct (1.222 at.pct) $\mathrm{W}$ and 3.073 wt pct (0.916 at.pct) Au with balance Fe. Dogbone-shaped creep samples with a gauge length of $12.5 \mathrm{~mm}$ and a cross section of $3 \mathrm{~mm}^{2}$ were cut by spark erosion, where the gauge length was chosen to be in the rolling direction. The samples were sealed in an evacuated quartz tube filled with 200 mbar ultra-high purity argon to prevent oxidation during annealing. After annealing for 5 hours at $1141 \mathrm{~K}\left(868{ }^{\circ} \mathrm{C}\right)$ in order to solutionize the solute atoms $\mathrm{Au}$ and $\mathrm{W}$, the samples were quenched into water. The as-quenched samples were examined using electron microscopy to assure that the samples are properly homogenized and that there is no precipitation before the creep tests (Figure S1). The solutionized as-quenched samples showed an average grain size of 103(37) $\mu \mathrm{m}$. Creep experiments until rupture were performed under vacuum at a constant temperature of $823 \mathrm{~K}\left(550^{\circ} \mathrm{C}\right)$ and with constant stress levels ranging from 170 to $235 \mathrm{MPa}$. The experiment conditions are summarized in Table I, while the experimental details of the test facility can be found in Reference 17.

Both the microstructure in the uniform deformation region and the actual fracture surfaces were characterized via scanning electron microscopy (SEM) using a JEOL JSM 6500F instrument equipped with energy-disperse X-ray spectroscopy (EDS), viz.: ThermoFisher UltraDry detector $\left(30 \mathrm{~mm}^{2}\right)$ with Noran System Seven software for data acquisition and analysis. To reveal the 
Table I. Summary of the experiment conditions and the creep results for the present $\mathrm{Fe}-\mathrm{Au}-\mathrm{W}$ alloy and the previous Fe-Au ${ }^{[19,20]}$ and $\mathrm{Fe}-\mathrm{W}^{[18]}$ alloys. All the experiments are performed at a fixed temperature of $823 \mathrm{~K}\left(550{ }^{\circ} \mathrm{C}\right)$

\begin{tabular}{|c|c|c|c|}
\hline Alloy & Stress $(\mathrm{MPa})$ & Strain Rate $\left(\mathrm{h}^{-1}\right)$ & Lifetime (h) \\
\hline Fe-Au-W & 170 & $2.162(3) \times 10^{-5}$ & 224.5 \\
\hline \multirow[t]{6}{*}{ Grain size: $103 \mu \mathrm{m}$} & 180 & $2.670(1) \times 10^{-5}$ & 141.6 \\
\hline & 190 & $2.625(3) \times 10^{-5}$ & 134.6 \\
\hline & 200 & $4.723(6) \times 10^{-5}$ & 97.4 \\
\hline & 210 & $7.53(2) \times 10^{-5}$ & 66.6 \\
\hline & 235 & $7.29(1) \times 10^{-5}$ & 50.6 \\
\hline & Stress exp & strain rate) $n=4.6$ & \\
\hline $\mathrm{Fe}-\mathrm{Au}{ }^{[19,20]}$ & 60 & $3.190 \times 10^{-5}$ & 641.7 \\
\hline \multirow[t]{4}{*}{ Grain size: $57 \mu \mathrm{m}$} & 80 & $5.080 \times 10^{-5}$ & 375.7 \\
\hline & 100 & $7.362 \times 10^{-5}$ & 209.9 \\
\hline & 117 & $2.748 \times 10^{-4}$ & 57.2 \\
\hline & Stress exp & strain rate) $n=3.4$ & \\
\hline $\mathrm{Fe}-\mathrm{W}[18]$ & 100 & $2.6(1) \times 10^{-5}$ & 1113 \\
\hline \multirow[t]{4}{*}{ Grain size: $127 \mu \mathrm{m}$} & 140 & $8.7(3) \times 10^{-5}$ & 236.4 \\
\hline & 160 & $2.0(5) \times 10^{-4}$ & 104.2 \\
\hline & 200 & $5.5(1) \times 10^{-4}$ & 56.8 \\
\hline & Stress exp & strain rate) $n=4.4$ & \\
\hline
\end{tabular}

precipitate crystal structure and composition, transmission electron microscopy (TEM) measurements were taken using a FEI $\mathrm{C}_{\mathrm{s}}$-corrected cubed Titan instrument. Elemental analysis was done with an Oxford Instruments EDX detector X-Max ${ }^{N}$ 100TLE. Lattice images were collected on a Gatan US1000 camera. ADF (Annular Dark Field) images and EDX spectra for elemental mapping were collected in STEM (scanning transmission electron microscopy) mode.

\section{RESULTS}

\section{A. Creep Results}

The strain versus time results of the Fe-Au-W alloy samples loaded at a fixed temperature of $823 \mathrm{~K}\left(550^{\circ} \mathrm{C}\right)$ but for different constant loads are shown in Figure 1(a). The derived steady-state strain rate (obtained by linear fitting of the strain levels covering 15 to 85 pct lifetime) and creep lifetime are presented in Figures 1(b) and (c), respectively. The initial strain of the samples increases with the increase in load. Soon after the loads are fully applied, the steady-state creep begins with a strain rate that remains about constant for most of the lifetime of these small samples. The transition from the steady-state creep to the tertiary creep occurs with a sharp increase in the strain rate, leading to a subsequent failure of the sample. The final strain ranges from 5 to 9 pct, while the strain attributed by the steady-state creep is below 1 pct, indicating a brittle nature of the ternary Fe-Au-W alloy. The steady-state strain rate fulfills the Sherby-Dorn equation $^{[24]} \dot{\varepsilon}_{S}=A d^{m} \sigma^{n} \exp (-Q / R T)$, where $A$ is a structure dependent constant, $d$ is the grain size, $m$ is the grain size exponent, $\sigma$ is the applied stress, $n$ is the stress exponent, $Q$ is the activation energy, $R$ is the gas constant, and $T$ is the temperature in kelvin. The corresponding stress exponent for the steady-state strain rate $n$ is 4.0(8), while the stress exponent derived from the lifetime corresponds to 4.6(5). The creep results of our previous $\mathrm{Fe}-\mathrm{Au}^{[19,20]}$ and $\mathrm{Fe}-\mathrm{W}^{[18]}$ alloys are also presented in Figures 1(b) and (c) for comparison. The Fe-W alloy has a grain size of $127 \mu \mathrm{m}$, which is comparable to the $\mathrm{Fe}-\mathrm{Au}-\mathrm{W}$ grain size of $103 \mu \mathrm{m}$; thus, the original data are shown. Since the grain size of the Fe-Au alloy was smaller $(57 \mu \mathrm{m})$, the strain rate and the lifetime of the Fe-Au alloy have been normalized using the grain size exponent $\left(m=-2^{[17]}\right)$. It can be seen that among these three alloys, the Fe-Au-W alloy has the lowest strain rate and the longest lifetime. The stress exponent for the Fe-Au-W and Fe-W alloys are comparable, indicating a similar creep-controlling mechanism. While for the Fe-Au alloy, the creep-controlling mechanism is likely to be different, especially in the low-stress regime. The strain rates and lifetimes for the three alloys with their experimental conditions are summarized in Table I.

\section{B. Microstructure of the Creep-Failed Samples}

The fracture surface of the creep-failed sample after having been exposed to an applied stress of $200 \mathrm{MPa}$ for $97.4 \mathrm{~h}$ is shown in Figure 2(a). The sample experienced a decohesive rupture at a grain boundary, which is consistent with the sudden transition from the steady-state creep to the tertiary creep, as shown in Figure 1(a). Some precipitates can be found on the fracture surface, both on the grain faces and at original grain corners or edges, as indicated by arrows. Some examples of formed cavities and precipitation healing are provided in Figure 2(b). The cavities are preferentially formed along the grain boundaries perpendicular to the stress direction (indicated by white arrow). Subsequently, the precipitates nucleate on the free creep cavity surface and then grow to fill the cavity gradually. In Figure 2(b), an example of a cavity fully filled by precipitation is indicated by a blue arrow. The precipitate is significantly enriched in $\mathrm{Au}$ (17.3 at.pct $\mathrm{Au}$ and 2.1 at.pct W). The 


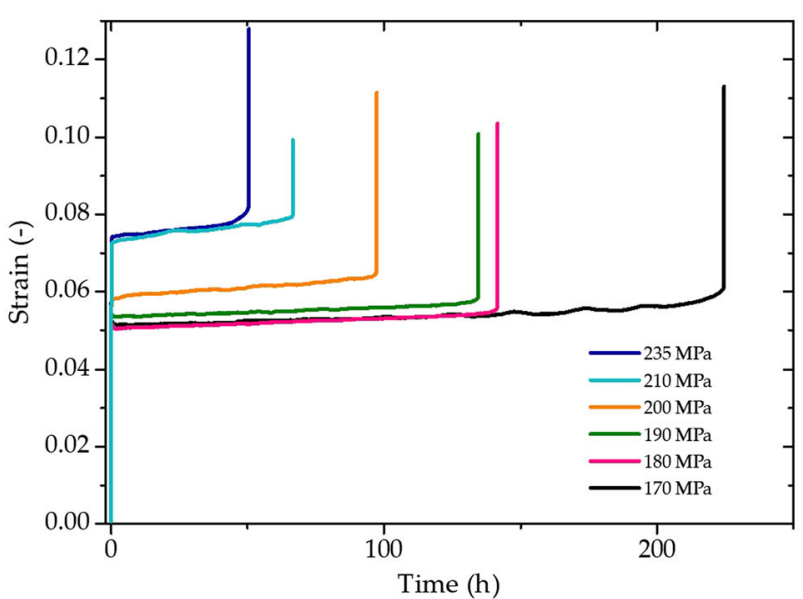

(a)

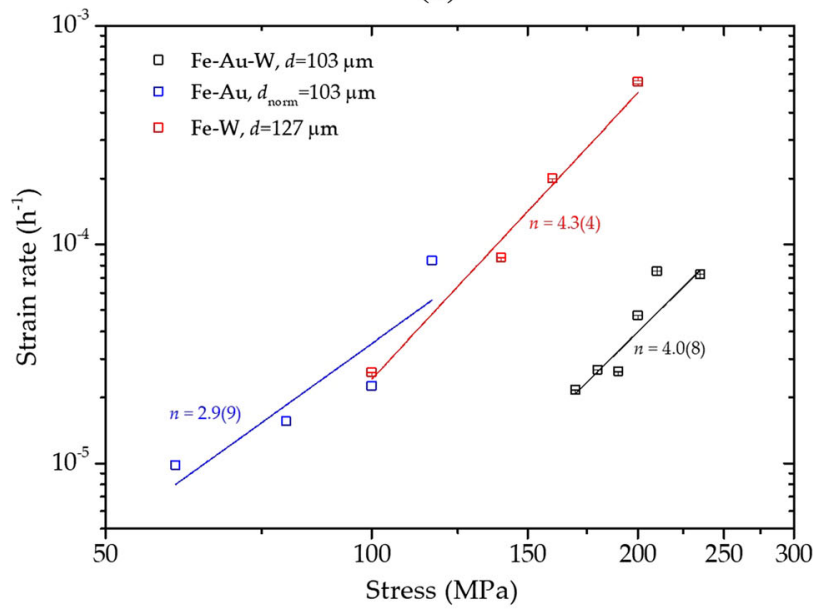

(b)

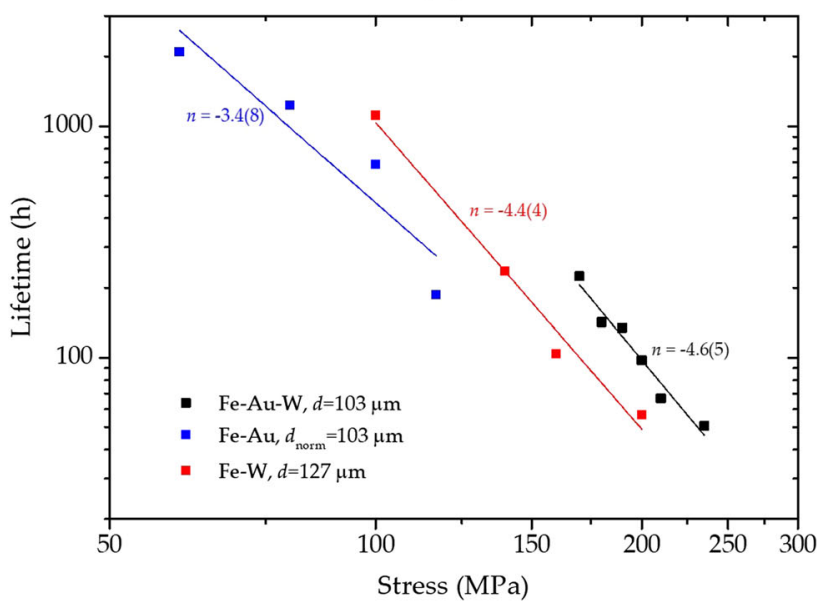

(c)

Fig. 1-(a) Creep curves for the Fe-Au-W alloy samples with different constant stress levels at a temperature of $823 \mathrm{~K}\left(550{ }^{\circ} \mathrm{C}\right)$. (b) Derived steady-stage strain rate and (c) creep lifetime as a function of applied stress. The strain rates and lifetimes of the previous $\mathrm{Fe}-\mathrm{Au}^{[19,20]}$ and $\mathrm{Fe}-\mathrm{W}^{[18]}$ samples are also summarized and compared in (b) and (c).

precipitate indicated by a yellow arrow inside of the cavity in Figure 2(b) is enriched in both $\mathrm{Au}$ and $\mathrm{W}$ (1.7 at.pct $\mathrm{Au}$ and 3.6 at.pct $\mathrm{W}$ ) with respect to the nominal value. The $\mathrm{Au}$ and $\mathrm{W}$ concentration profiles along the black line crossing the precipitate in Figure 3(b) are measured with EDS and are presented in Figure 2(c). The precipitate is enriched in Au with a peak concentration of about 17 at.pct, while the W concentration remains around the nominal value. The $\mathrm{Au}$ concentration is likely to be underestimated, given the limited resolution of the EDS. In agreement with the binary $\mathrm{Fe}-\mathrm{Au}$ system, ${ }^{[20]}$ uniformly dispersed disk-shaped nano-sized Au-rich particles are found within the matrix, as shown in Figures 2(b) and (d). In contrast to the $\mathrm{Fe}-\mathrm{Au}$ binary system, no micron-scale $\mathrm{Au}$ depletion zone was observed in the current ternary $\mathrm{Fe}-\mathrm{Au}-\mathrm{W}$ alloy. As indicated in Figure 2(d), the depletion zone has a maximum width of approximately $0.5 \mu \mathrm{m}$. The reduced width of the Au depletion zone suggests a reduction in the effective $\mathrm{Au}$ volume diffusivity inside the bulk of the ternary Fe-Au-W alloy due to a suppression of the extensive subgrain formation observed in the binary $\mathrm{Fe}-\mathrm{Au}$ alloy. ${ }^{[17,20]}$

It is important to note that the precipitates are triggered by the formation of the cavities (instead of triggering the cavities). In the creep-failed samples, many precipitates formed in the cavities show irregular shapes, and their shapes match the geometry of the corresponding cavities, indicating a cavity-triggered healing behavior. More detailed discussions can be found in ${ }^{[17]}$ and ${ }^{[19]}$

The composition of a collection of precipitates located on samples with varying creep lifetimes is analyzed by EDS and the results are summarized in Figure 3. The vertical dotted line corresponds to the nominal $\mathrm{Au}$ concentration and the horizontal dotted line corresponds to the nominal $\mathrm{W}$ concentration. The data points located in the blue-shaded region and the yellow-shaded region correspond to the precipitates enriched in $\mathrm{W}$ and in $\mathrm{Au}$, respectively. The data points in the non-shaded region represent the precipitates enriched in both $\mathrm{Au}$ and W. It can be observed that the precipitates have a composition that ranges up to 20 at.pct Au and 8 at.pct $\mathrm{W}$. Independent of the lifetime most of the precipitates are either enriched in $\mathrm{Au}$ or enriched in $\mathrm{W}$, and only a few precipitates are enriched in both $\mathrm{Au}$ and W. This indicates that the Au-rich and $\mathrm{W}$-rich precipitates are formed independently, and that within the experimental resolution of the EDS, Au-rich and W-rich precipitates rarely occupy the same cavity.

In order to characterize the precipitation behavior in more detail, additional TEM experiments were performed. Figure 4 shows the TEM results for the sample that was exposed to a stress of $190 \mathrm{MPa}$ at a temperature of $823 \mathrm{~K}\left(550{ }^{\circ} \mathrm{C}\right)$. As shown in Figure 4(a), disk-shaped precipitates are found uniformly distributed within the matrix. The disks have a diameter of 40 to $150 \mathrm{~nm}$ and a diameter-to-thickness ratio ranging from 5 to 10 . An interface relationship of $(015)_{\text {matrix }} \|(116)_{\text {precipitate }}$ and orientation relationships of [002] matrix ||$[002]_{\text {precipitate }}$ and $[200]_{\text {matrix }}||[110]_{\text {precipitate }}$ are found between the matrix and the disk-shaped precipitates. As shown in the elemental map in Figure 4(b), the disks are enriched in $\mathrm{Au}$, while the $\mathrm{W}$ distribution is about uniform. A line scan across a precipitate (shown in Figure S2) shows an $\mathrm{Au}$ 

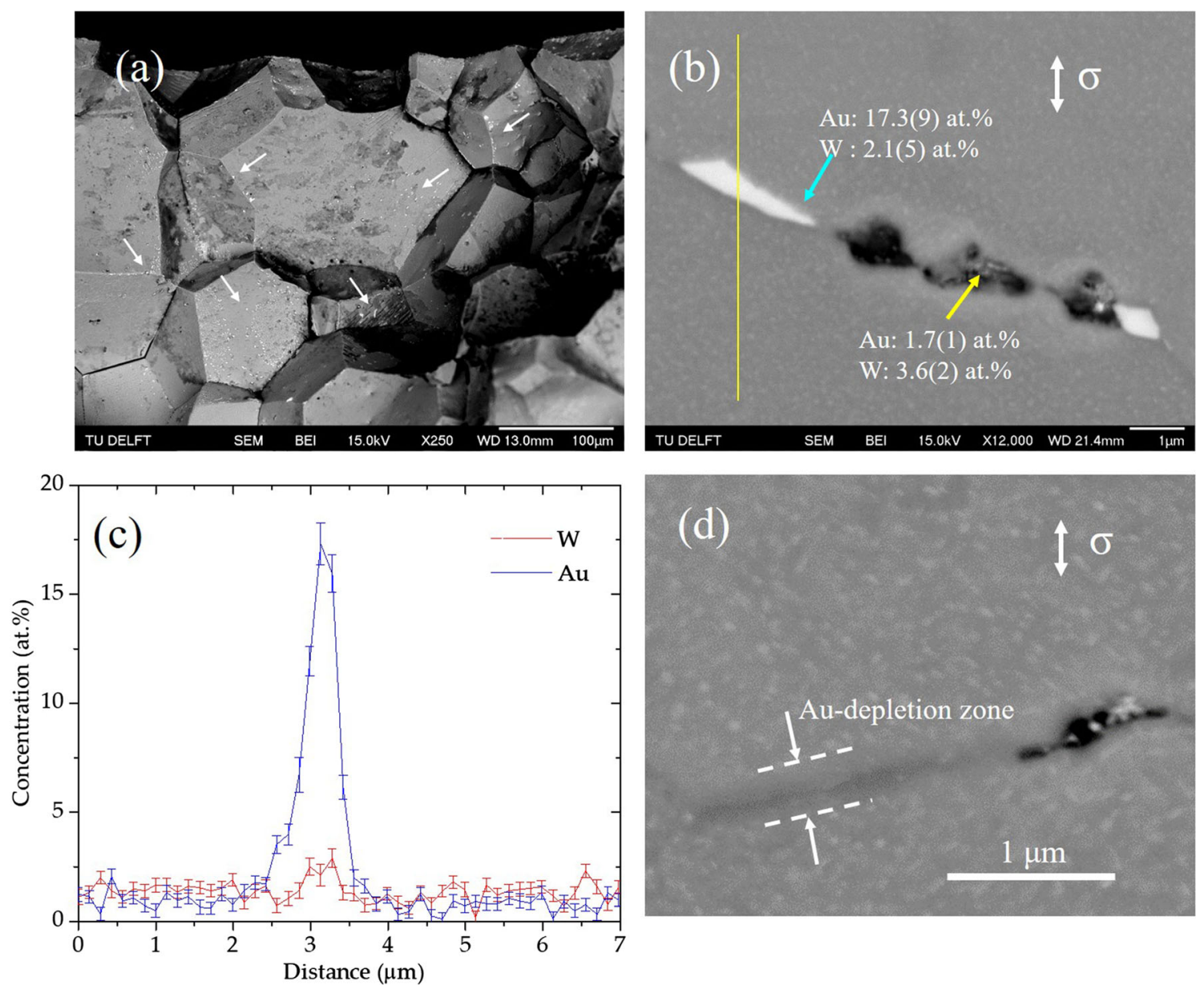

Fig. 2-Scanning electron microscopy data for Fe-Au-W alloy sample after creep at a constant stress of $200 \mathrm{MPa}$ at $823 \mathrm{~K}\left(550{ }^{\circ} \mathrm{C}\right)$. (a) Fracture surface of the creep-failed sample. The white arrows indicate the precipitates. $(b)$ Micrograph for the same sample. The blue arrow indicated precipitate is significantly enriched in Au while the yellow arrow indicated precipitate is enriched in both Au and W. (c) Composition profile of the line scan in (b). (d) Micrograph of the same sample. Au-rich disks and an Au depletion zone can be observed (Color figure online).

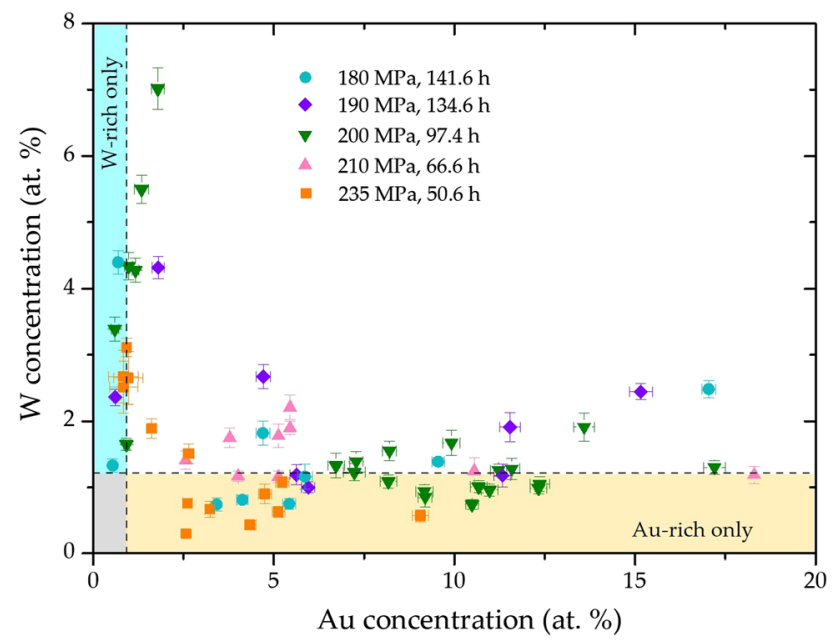

Fig. 3 - Collected precipitate compositions for precipitates in creep samples with different stress levels and creep lifetimes. The vertical dotted line and the horizontal dotted line indicate the nominal Au concentration and the nominal $\mathrm{W}$ concentration, respectively. concentration of 56 at.pct in the center. The disks have an $f c c$ structure, with a lattice parameter of $a_{0}=3.95(6) \AA$, corresponding to a gold concentration of 61(20) at.pct for the precipitate. The gold concentration of the surrounding matrix is lower than the nominal value (about 0.6 at. pct). Au-rich disks are found to be connected to dislocations (Figure 4(c)). Since no disks were observed in an as-quenched sample, it can be concluded that the disk-shaped precipitates nucleate from the dislocations, which are generated during creep. No W-rich precipitates are found in the matrix of the creep-failed sample. On the grain boundaries with no cavities, many precipitates with a size of 5 to $50 \mathrm{~nm}$ are observed (Figure 4(d)). These precipitates are enriched in either $\mathrm{Au}$ or $\mathrm{W}$ and the two types of precipitates are usually found in contact with each other (Figure 4(e)).

\section{Fracture Surface}

To clarify the formation of creep cavities, precipitation on the creep cavity surface and the interaction between $\mathrm{Au}$-rich and $\mathrm{W}$-rich precipitates, the fracture surfaces after creep were examined. The brittleness of the material and the decohesive rupture enabled a direct observation 

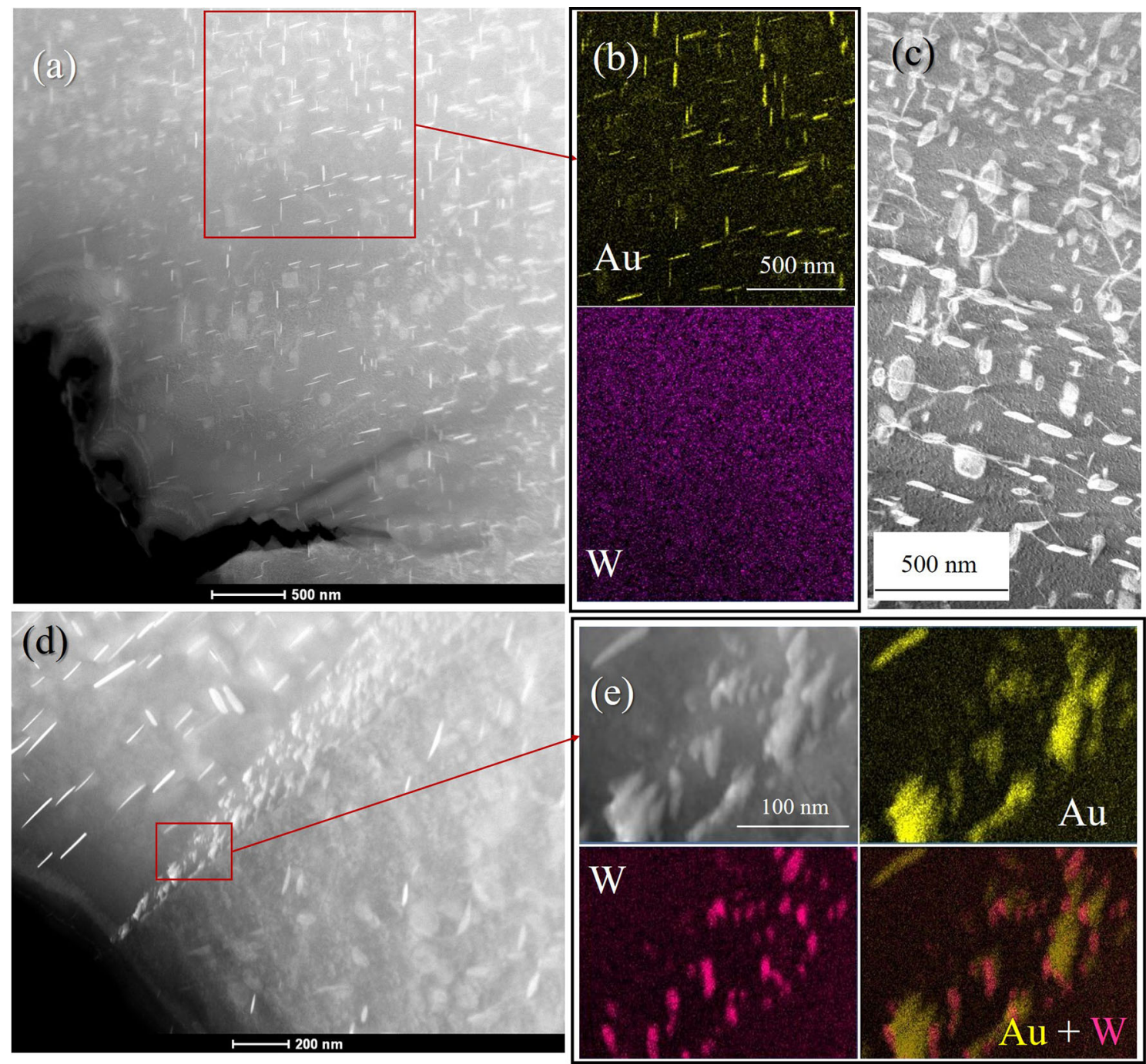

Fig. 4-TEM results for the Fe-Au-W alloy sample after creep at a stress of $190 \mathrm{MPa}$. (a) Disk-shaped precipitates in the matrix. (b) Elemental distribution of $\mathrm{Au}$ and $\mathrm{W}$ for the selected square area in (a). (c) Disk-shaped precipitates (with 3 perpendicular orientations) connected with dislocations (lines) are observed in the matrix. (d) Precipitates on a grain boundary without cavities. (e: Elemental distribution of Au and W for the selected square area in (d). By overlapping the distribution of $\mathrm{Au}$ and $\mathrm{W}$, one can see that the Au-rich and W-rich precipitates are in contact.

of the grain boundary fracture, with complementary mirror-like information from both sides of the fracture surface. Figure 5 shows the fracture surface of the creep-failed sample after creep at a stress of $200 \mathrm{MPa}$. Two kinds of cavities can be observed in Figures 5(a) and (b): (i) large rectangular-shaped cavities (box 1 in Figure 5(f)) and (ii) small ellipsoid-shaped cavities (box 2 in Figure 5(f)), which are often fully filled with precipitation. In this case, most of the precipitates stick to one side of the broken sample (side A), but generally, the precipitates are found on both surfaces (see the neighbor grain on the right-hand side). By comparing the precipitate shape with the shape of the corresponding dent on the opposite surface, it seems that the ellipsoid cavities are fully filled by the micro-sized precipitates.

As shown in Figures 5(c) through (f), some nanosized precipitates (significantly smaller than the ellipsoidal particles) are found inside the rectangular cavities. Unlike the ellipsoidal micro-sized precipitates, the nano-sized precipitates are distributed over the cavity surface, showing only a limited degree of filling. To determine the composition of the two types of the precipitates, the atomic concentrations of $\mathrm{Fe}, \mathrm{Au}$ and $\mathrm{W}$ were mapped using EDS, as shown in Figure 5(c). The ellipsoidal micro-sized particles correspond to Au-rich precipitates (with a highest observed concentration of about 8 at.pct $\mathrm{Au}$ ), while the nano-sized particles in the rectangular cavities are enriched in $\mathrm{W}$ (up to about 5 at.pct W). A closer observation of the cavities covered with nano-sized particles yields more detailed information. As shown in Figures 5(d) and (e), spots 1 and 4 are only enriched in $\mathrm{W}$, while spots 2 and 3 are enriched in both $\mathrm{Au}$ and $\mathrm{W}$. The nano-sized particles in the rectangular cavities are generally enriched in $\mathrm{W}$, but some of the nano-sized particles are found to be enriched in $\mathrm{Au}$. By comparing this observation with 

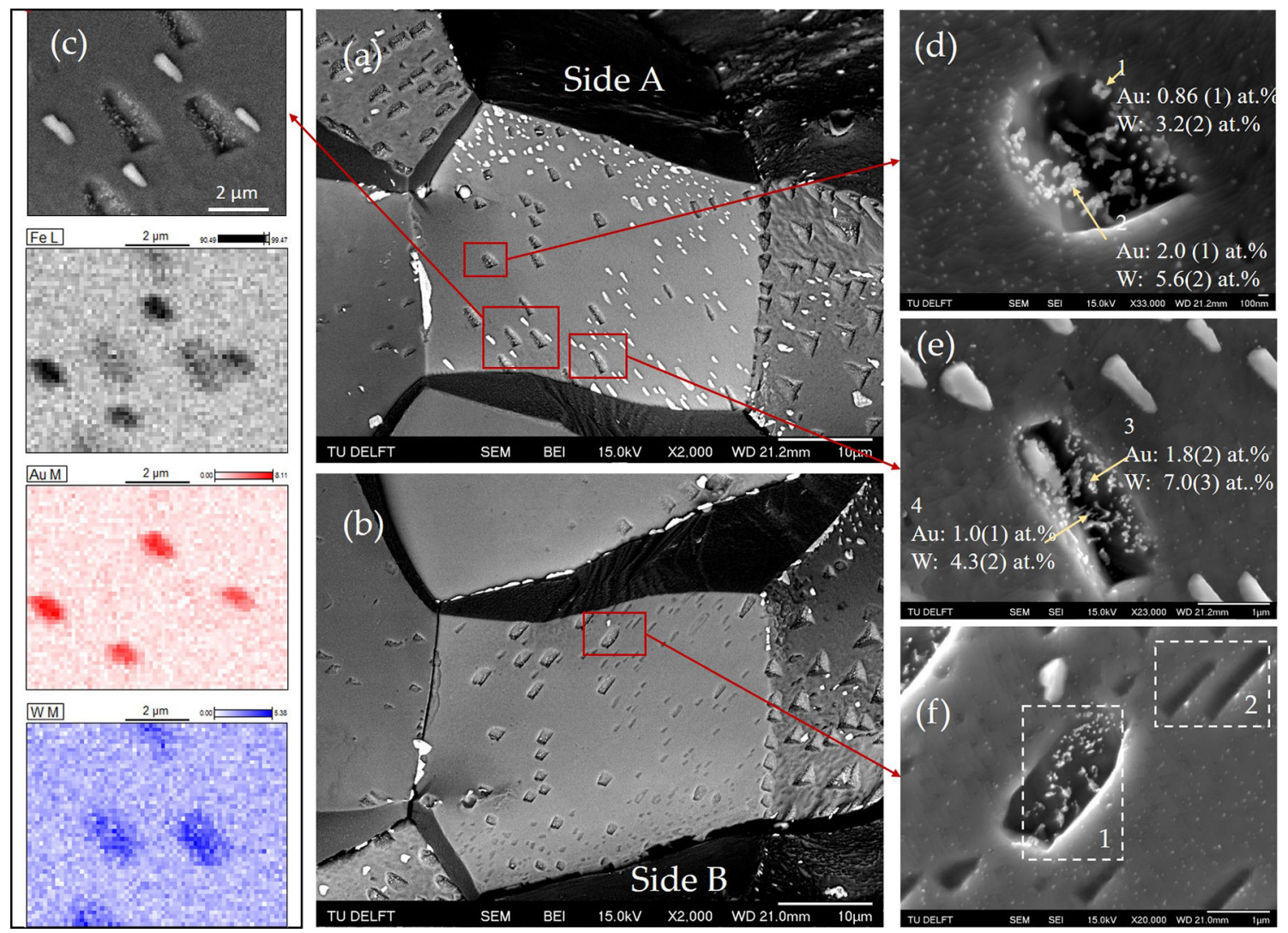

Fig. 5- $(a)$ and $(b)$ : Both sides of a grain boundary fracture surface of the Fe-Au-W alloy sample after creep at a stress of $200 \mathrm{MPa}$. (c): Elemental distribution of $\mathrm{Fe}, \mathrm{Au}$ and $\mathrm{W}$ for the selected square area in (a). (d) through $(f)$ : Precipitates of different sizes are found in the cavities: the micro-sized precipitates in (e) are Au-rich, while the nano-sized particles inside of the rectangular cavities are generally W-rich, but some Au-rich nano-sized particles are also found. The micro-sized Au-rich and nano-sized W-rich precipitates rarely coexist, but an occasional example of coexistence is found in (e).

the TEM results in Figures 4(d) and (e), where nano-sized Au-rich and W-rich precipitates are both found on the grain boundary, it can be concluded that spots 2 and 3 correspond to a situation where nano-sized Au-rich and W-rich particles both are located inside the rectangular cavity, and that these two types of nano-particles are in direct contact with each other.

Although it is experimentally found that nano-sized Au-rich and W-rich particles can be formed within the same cavity, in most cases the cavity is filled with either Au-rich or W-rich precipitates. In Figure 5(f), boxes 1 and 2 provide some insight in the interaction between Au-rich and W-rich precipitates during healing. In the rectangular cavity in box 1 only nano-sized particles are found. On the contrary, the two cavities in box 2 are filled with Au-rich precipitates, which are attached to the opposite side (side A) of the fracture surface, and the cavities on side B show a very clean counterpart without nano-sized $\mathrm{W}$-rich particles. In most of the examined cavities, the micro-sized Au-rich and the nano-sized W-rich precipitates demonstrate a persistent reluctance to coexist with each other, within the resolution of the EDS. A rare cavity showing both micro-sized Au-rich precipitates and nano-sized W-rich precipitates is shown in Figure 5(e). These fracture surface observations agree well with the result in Figure 3: the precipitates are enriched in either $\mathrm{Au}$ or $\mathrm{W}$ and only few of the cavities are found to be filled by both types of precipitates.

In addition to the precipitates in the cavities, some uniformly distributed nano-sized particles are also found in the area around the cavities, as can be seen from Figures 5(d) through (f). This area of the fracture surface without cavities was intact at the end of the steady-state creep and only formed in the rapidly evolving final (tertiary) creep stage. EDS results show that these particles are enriched in W. No Au-rich particles are found on the fracture surface around the cavities.

The fracture surface of the creep-failed sample at a stress of $235 \mathrm{MPa}$ is presented in Figures 6(a) through (d). With a shorter lifetime due to a higher stress, the size of both the cavities and precipitates is generally smaller. Two regions can be distinguished from the fracture surface: $(i)$ a region with a net-shaped pattern in the vicinity of the grain edges and (ii) a flatter interior region. In the flatter region, the precipitate distribution shows a preference towards the grain edges, indicating that the cavities located on the grain edges or corners are preferentially healed. The net-shaped pattern may be induced by subgrain boundaries and dislocation cells that have formed in the initial creep stage. ${ }^{[25]}$ Similar to the creep-failed sample at a stress of $200 \mathrm{MPa}$ presented 

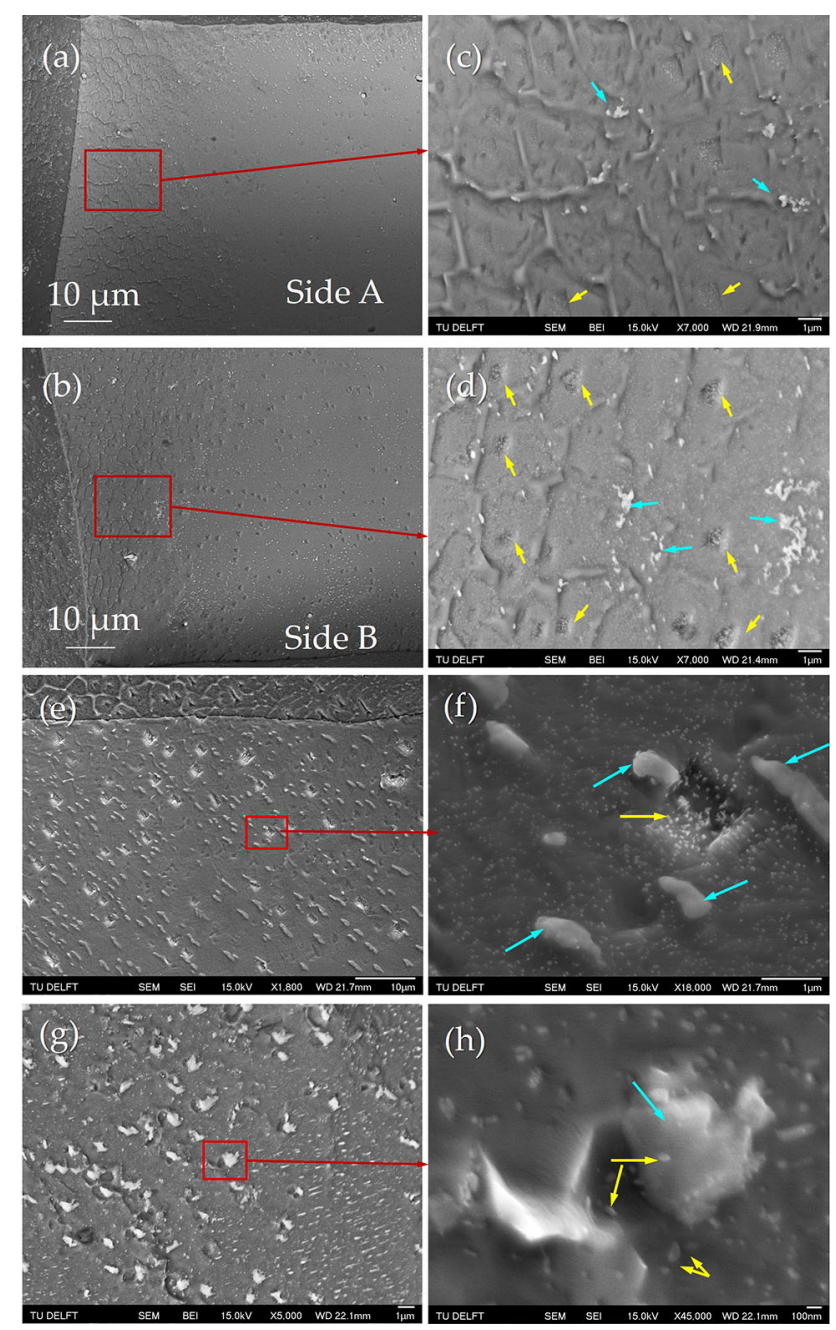

Fig. 6- (a) through $(d)$ : The fracture surfaces for the Fe-Au-W alloy sample after creep at a stress of $235 \mathrm{MPa}$. (e) through $(h)$ : The fracture surfaces for the $\mathrm{Fe}-\mathrm{Au}-\mathrm{W}$ alloy sample after creep at a stress of $180 \mathrm{MPa}$. The blue arrows indicate Au-rich precipitates while yellow arrows indicate $\mathrm{W}$-rich particles (Color figure online).

in Figure 5, the same two types of precipitates are observed on the fracture surface for a sample with a relatively short lifetime. In Figures 6(a) through (d) the relatively large Au-rich precipitates and the nano-sized W-rich particles, which are scattered over the surface of the rectangular cavities, are indicated by the yellow and blue arrows, respectively. The morphology of the Au-rich precipitates is different from those observed in the samples with a relatively long lifetime. Instead of an ellipsoidal shape, the Au-rich particles have a more irregular shape, especially in the region with the net-shaped pattern. It is worth to note that in Figures 6(c) and (d), the cavities and the Au-rich precipitates do not have a one-to-one correspondence, as observed in the creep-failed sample at a stress of $200 \mathrm{MPa}$. Some of the cavities on side A do not have a corresponding precipitate on side $\mathrm{B}$, indicating that the sample is in an early stage of filling where the Au-rich precipitation has just started to take place, initiated by the formation of the cavity.
In Figures 6(e) through (h), the fracture surface of the creep-failed sample at a stress of $180 \mathrm{MPa}$ with a longer lifetime of 141.6 hours is presented. The two types of precipitates with micron-sized Au-rich precipitates and W-rich nanoscale precipitates, as well as the reluctance for coexistence of Au-rich and $\mathrm{W}$-rich precipitates in a single cavity, are evident from Figures 6(e) and (f). These observations are consistent with the results for the samples with a stress of $200 \mathrm{MPa}$ (97.4 hours) and $235 \mathrm{MPa}$ (50.6 hours). However, in Figures 6(g) and (h), a large number of cavities are half-filled by Au-rich precipitates (indicated by the blue arrow) and are decorated by the nano-sized $\mathrm{W}$-rich particles (indicating by yellow arrows) over the cavity surface. Compared with the observations from samples with shorter lifetimes, it is most probable that these cavities are initially occupied by both W-rich and Au-rich nano-sized precipitates but that during the relatively long lifetime the Au-rich precipitates have overgrown the W-rich precipitates by their faster kinetics.

\section{DISCUSSION}

\section{A. Mechanism of Selective Healing}

It was experimentally observed that the creep cavities were fully or partially filled by precipitates that segregated from the homogeneous supersaturated matrix. As indicated in Figure 2, both the cavities and the precipitates showed a preference to form at grain boundaries oriented perpendicular to the stress direction or at the grain boundary edges. The observed precipitates are different in composition, size, shape, spatial distribution and degree of filling. As shown in Figures 5 and 6, the Au-rich precipitates are usually found to be micron-sized with ellipsoidal shapes, while the W-rich particles are usually roundish and nano-sized. Some nano-sized Au-rich particles are also found in contact with W-rich precipitates. Many micron-sized Au-rich precipitates on the fracture surface show complementary shapes with the cavities they fill on either side of the fracture surface, indicating that the cavities are fully filled. The W-rich precipitates, on the other hand, are scattered over the cavity surfaces, generally showing only a limited degree of filling. For the samples with shorter lifetimes (less than 100 hours), the two types of precipitates are in most cases not found to coexist on a micron-scale: the cavities are filled by either micron-sized Au-rich or nano-sized W-rich particles, while coexistence only happens occasionally. However, nanosized Au-rich and W-rich precipitates can be found concurrently in the same cavities. This observation from the fracture surfaces is consistent with the precipitates composition distribution shown in Figure 3, where most of the precipitates are enriched in either $\mathrm{Au}$ or $\mathrm{W}$. The few precipitates enriched in both $\mathrm{Au}$ and $\mathrm{W}$ may correspond to $(i)$ the occasionally observed coexistence behavior of micron-sized Au-rich precipitate and nano-sized W-rich particles (Figure 5(e)) or (ii) the coexistence of nano-sized Au-rich and W-rich particles (Figure 5(d) and (e)). 
It is worth to note that both Au-rich and W-rich precipitates show an obvious site selectivity, i.e., the precipitates form exclusively on free surfaces. No precipitation takes place within the bulk, except for the nano-sized, disk-shaped $\mathrm{Au}$ precipitates (Figures 2(d) and 4), which were also observed in the binary $\mathrm{Fe}-\mathrm{Au}$ system. ${ }^{[17,20]}$ These Au-rich disks were found to be connected to dislocations (Figure 4(c)), which act as nucleation sites, and can be consumed by the nucleation and growth of the healing precipitates in the nearby grain boundary cavities. After the dis$\mathrm{k}$-shaped precipitates are consumed, a depletion zone forms in the vicinity of the grain boundary (Figure 2(d)). The site selectivity results from the strain energy generated by the misfit between the solute and the matrix atoms.

The healing mechanism of the Fe-Au-W system is illustrated in Figure 7. In stage I (Figure 7(a)), the as-quenched sample is homogeneous without any matrix precipitates or grain boundary segregation (as confirmed in Figure S1). When the sample is exposed to high temperature and stress (stage II), solute atoms segregate on the grain boundaries in the form of nano-sized Au-rich and W-rich precipitates. Meanwhile, dislocations are generated, which act as nucleation sites for the formation of Au-rich disk-shaped precipitates within the matrix. As indicated in Figure 7(b), the Au-rich disks, which are connected to dislocations, form uniformly within the matrix and remain stable until a cavity is formed nearby. When a cavity is generated (stage III), the healing takes place. Since the grain boundary diffusivity is orders of magnitude larger than the bulk diffusivity, a 1D bulk diffusion towards the grain boundary takes place once a free surface in the form of a creep cavity is generated. The solute Au atoms in the matrix diffuse towards the grain boundary as the grain boundary serves as a fast path in transferring the healing solute towards the cavity. During this process, the nano-sized grain boundary Au-rich precipitates (formed in stage II) are consumed via grain boundary diffusion. Meanwhile, the nano-sized W-rich precipitates (formed in stage II) are left on the grain boundary, since

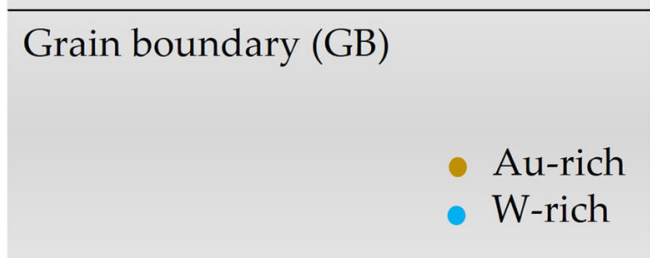

(a) Stage I

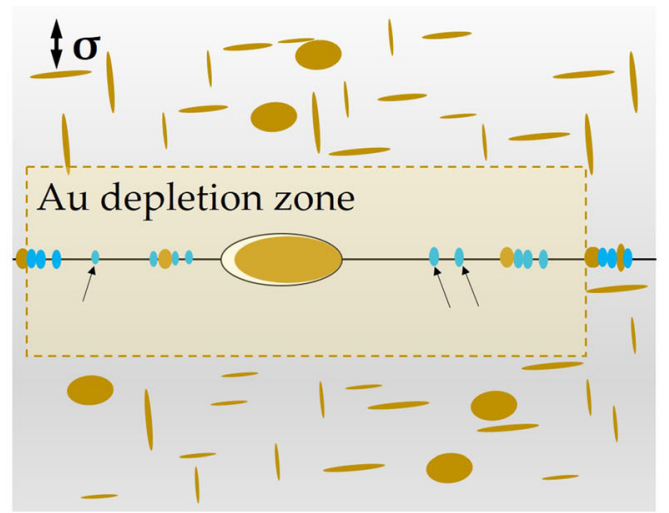

(c) Stage III

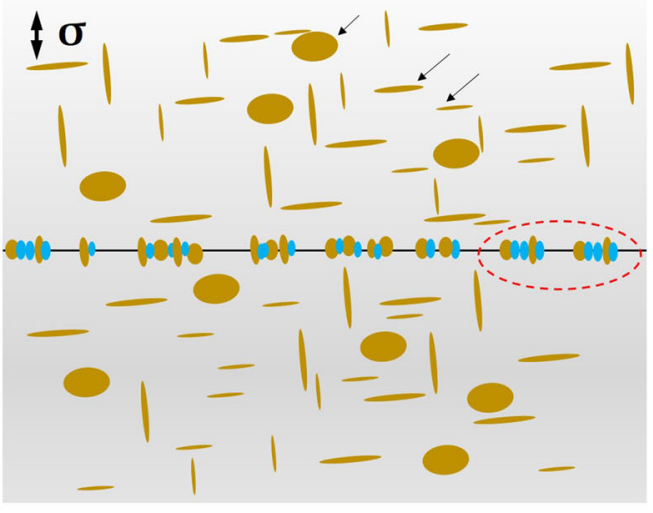

(b) Stage II

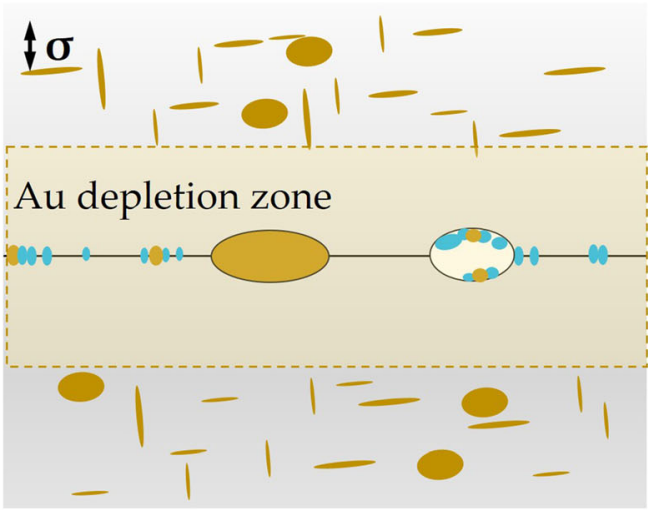

(d) Stage IV

Fig. 7-Mechanism of cavity formation and solute healing. (a) The as-quenched sample, showing a homogenized composition without matrix precipitation or grain boundary segregation. (b) When the stress is applied, dislocation-connected Au-disks (indicated by the black arrows) form uniformly in the matrix. Meanwhile, the grain boundary precipitation (enriched in either Au or W, as indicated by the dashed line) forms. (c) When a cavity is generated, an Au-rich precipitate fills the cavity by 1D diffusion from the bulk to the grain boundary and grain boundary diffusion towards the cavity. The Au-rich precipitates on the grain boundary is consumed and W-rich particles are left on the grain boundary (indicated by the black arrows). An Au depletion zone is subsequently generated due to the consumption of the Au-disks in the matrix. (d) A cavity forms within the Au depletion zone and is partly filled by nano-sized W-rich precipitates (and some sparse nano-sized Au-rich precipitates). 
the diffusivity of $\mathrm{W}$ is much slower than that of $\mathrm{Au}$. This phenomenon can be observed in Figures 5(d) through (f), where W-rich precipitates can be found on the fracture surface around the creep cavities. If the amount of solute and precipitated $\mathrm{Au}$ atoms on the grain boundary is not enough to fully fill the cavity, the disk-shaped Au-rich precipitates in the matrix are subsequently consumed. In this situation, a depletion zone for $\mathrm{Au}$ is generated in the vicinity of the grain boundary. The width of the depletion zone is either determined by the volume of the cavity (when the cavity is small) or by the bulk solute diffusion length (when the cavity is large). This phenomenon is illustrated in Figure 7(c) (and supported by the data in Figure 2(d)). When a cavity forms in the depletion zone for Au (stage IV), it can only be filled by W-rich precipitates, as illustrated in Figure 7(d). Unlike the Au-rich precipitates, the $\mathrm{W}$-rich precipitates only provide a limited degree of healing, due to the lower diffusivity of $\mathrm{W}$. Some nano-sized Au-rich particles can also form in these new-formed cavities, but the precipitates are predominantly enriched in W (as observed in Figure 5(c)).

\section{B. Filling Ratio}

Analogous to our previous 3D nano-tomography studies on self-healing of creep damage in $\mathrm{Fe}-\mathrm{Au}^{[19]}$ and $\mathrm{Fe}-\mathrm{W}^{[18]}$ alloys, the healing efficiency can be estimated from the filling ratio of the cavities (volume of the precipitate divided by the total volume of the cavity in which it formed). The estimated filling ratios (see supplementary information for details), obtained from the experimental fracture surfaces for the creep-failed samples at different stress levels are shown in Figure 8. As expected, a higher filling ratio is achieved at a lower stress (and correspondingly a longer lifetime). For the lowest stress of $180 \mathrm{MPa}$ (with the longest lifetime) a filling ratio of 71 pct was achieved. According to our previous research, ${ }^{16,18,19]}$ the cavities already start to form at the beginning of the creep. However, the healing

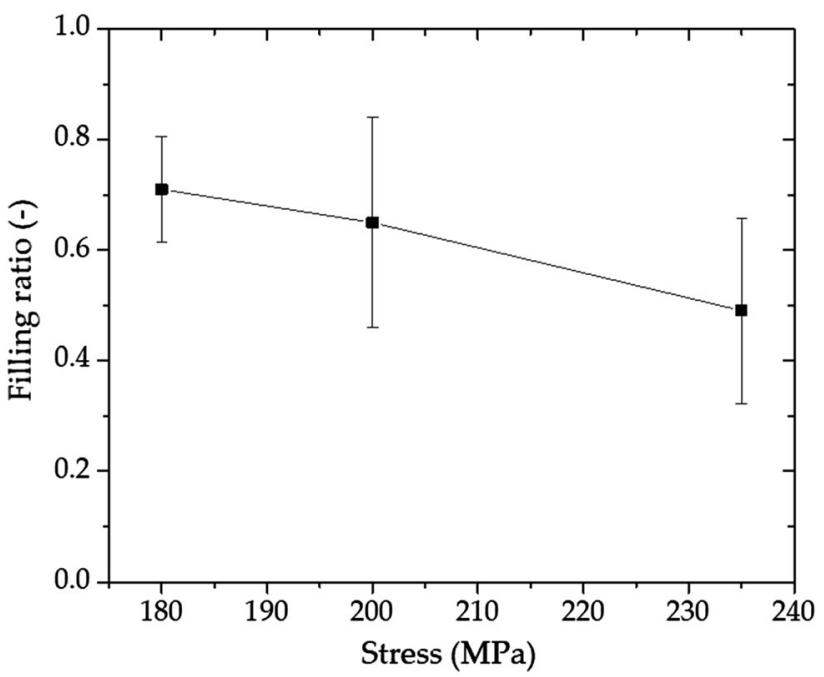

Fig. 8-Average filling ratio for the Fe-Au-W alloy samples after creep at a stress of 180,200 and $235 \mathrm{MPa}$. only starts after the cavity reaches a certain volume. Therefore, if the sample lifetime is short, the precipitates may not have had enough time to grow and catch up with the growth of the cavities. Owing to the relatively short lifetime, the highest stress of $235 \mathrm{MPa}$ results in the lowest filling ratio.

\section{The Size of the Precipitates and the Creep Cavities}

In our previous studies, ${ }^{[18,19]}$ the time evolution of the average volume for a precipitate (or a cavity) was fitted by $V=k t^{n}$, where $V$ is the average volume of a precipitate a cavity, $t$ is the time, $k$ and $n$ are constants that dependent on the material and the condition whether or not the precipitates (or cavities) are linked to their neighbors. For all the precipitates and isolated cavities, $n=0.8$. For the linked cavities, the exponent $n$ has a higher value of 1.3.

To compare the results of the current ternary system with the previous binary alloys, the average diameters of the cavities and precipitates as a function of time are
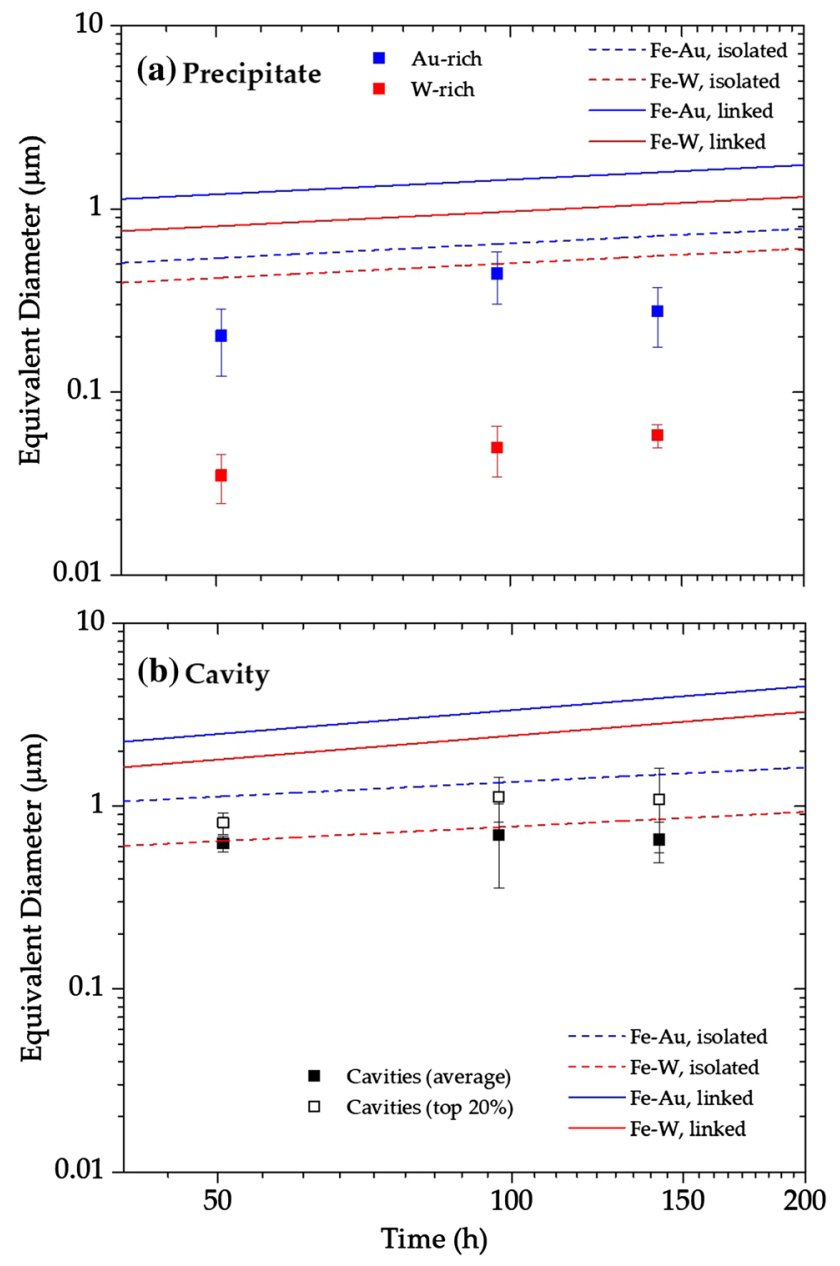

Fig. 9-Evolution of the size of $(a)$ the precipitates and $(b)$ the cavities as a function of time. The dotted curves represent the experimental data for the binary $\mathrm{Fe}-3 \mathrm{Au}^{[19]}$ and $\mathrm{Fe}-4 \mathrm{~W}^{[18]}$ systems. The equivalent diameter corresponds to $d=(6 / \pi)\left(k t^{n}\right)^{1 / 3}$, where $k$ and $n$ are the experimentally determined growth constant and growth exponent, respectively. 
shown in Figure 9 (examples of the size distributions are presented in Figure S3). For the present ternary alloy, the average sizes of the cavities and the Au-rich precipitates show an increase with time, although at a stress of $180 \mathrm{MPa}$ (with a lifetime of 141.6 hours) both the Au-rich precipitates and the cavities are smaller than their counterparts at a stress of $200 \mathrm{MPa}$ (with a lifetime of 97 hours). Although the average cavity size at a stress of $180 \mathrm{MPa}$ is smaller than that at $200 \mathrm{MPa}$, the size of the top 20 pct largest cavities in the two samples are comparable. In fact, as shown in Figure 9(b), the difference between the top 20 pct cavity size and the average cavity size increases for a decrease in stress (and correspondingly an increase in lifetime). The top 20 pct cavities generally correspond to the rectangular cavities (which are partially filled by W-rich cavities), while the average cavity sizes are attributed to both the partially filled and the fully filled cavities. The partially filled cavities grow continuously, while the growth of the fully filled cavities is stopped (or strongly suppressed).

By comparing the cavity evolution among the three systems, a smaller cavity growth rate is observed for the new ternary alloy. In the Fe-Au-W alloy, Au-rich precipitates are smaller in size than both the Au-rich precipitate in $\mathrm{Fe}-\mathrm{Au}$ system and the W-rich Laves precipitates in $\mathrm{Fe}-\mathrm{W}$ system. The most pronounced difference lies in the size of the $\mathrm{W}$-rich precipitates with only 30 to $60 \mathrm{~nm}$ in diameter in the $\mathrm{Fe}-\mathrm{Au}-\mathrm{W}$ system, which is one order of magnitude smaller than the precipitates in the Fe-W binary system. The formation of W-rich precipitates has apparently been suppressed strongly in the ternary alloy.

\section{Number Density and Volume Fraction}

The number of cavities and of Au-rich precipitates per unit of fracture surface area (2D number density) for the ternary Fe-Au-W alloy is now compared with the data for the binary Fe-Au alloy. ${ }^{[19]}$ Assuming that: (1) all the cavities and precipitates are located on grain boundaries and (2) the decohesive rupture takes place along the grain boundaries whose orientation angles to the stress direction are larger than $45 \mathrm{deg}$ (about perpendicular to the applied stress). Then the 2D number density can be converted from our current measurement to a $3 \mathrm{D}$ volume number density. According to our previous study ${ }^{[20]}$ about $2 / 3$ of the precipitates are located on the grain boundaries with an $\mathrm{GB} /$ stress orientation angle larger than $45 \mathrm{deg}$. The volume number density is thus estimated to be $n_{V}=(3 / 2) n_{A} / d_{G}$ for the cavities and $n_{V}=3 n_{A} / d_{G}$ for the Au-rich precipitates, where $d_{G}$ is the average grain size and $n_{A}$ is the areal number density of precipitates or cavities (average of the observation on both sides of the fracture surface). Assuming a spherical shape for the cavities (precipitates), the corresponding volume fraction of the cavities (precipitates) can be written as $f_{V}=(\pi / 6) d^{3} n_{V}$, where $(\pi / 6) d^{3}$ corresponds to the average volume of the cavities (precipitates). The results are summarized in Table II. Compared to the binary $\mathrm{Fe}-\mathrm{Au}$ alloy, the ternary $\mathrm{Fe}-\mathrm{Au}-\mathrm{W}$ alloy has smaller cavities and precipitates, but the number density of the cavities and precipitates is higher. In the binary system a lower stress (and thus a longer lifetime) results in larger cavities, larger precipitates and lower number densities. This phenomenon is related to a precipitate-precipitate coalescence and cavity-cavity linking, ${ }^{19]}$ which can result in an increase in particle size and a decrease in number density. Considering the larger stresses applied to the ternary alloy, as well as its brittle nature, it can be concluded that in the ternary alloy the coalesce of the cavities and precipitates is limited when the stress is higher than $180 \mathrm{MPa}$.

\section{E. Healing Kinetics}

The volume diffusivity of solute $\mathrm{Au}$ and $\mathrm{W}$ in $b c c$-iron at a temperature of $823 \mathrm{~K}\left(550{ }^{\circ} \mathrm{C}\right)$ corresponds to $7.4 \times 10^{-19} \mathrm{~m}^{2} \mathrm{~s}^{-1}$ and $3.3 \times 10^{-21} \mathrm{~m}^{2} \mathrm{~s}^{-1},{ }^{[26]}$ respectively. Given the dilute nature of the ternary alloy it is assumed that these values also apply to the ternary alloy. As no values have been reported for the grain boundary diffusivity of $\mathrm{Au}$ and $\mathrm{W}$ in $b c c$-iron, the $\mathrm{Fe}$ self-diffusivity along the grain boundary is taken, which amounts to $2.4 \times 10^{-14} \mathrm{~m}^{2} \mathrm{~s}^{-1}$. [27] The grain boundary diffusivity is orders of magnitude higher than the volume diffusivity, indicating that volume diffusion is the rate-controlling process. In this situation, the diffusion of the solute atoms towards the creep cavities can thus be simplified by a 1D diffusion, ${ }^{[28]}$ i.e., the supersaturated solute atoms diffuse towards the nearest

Table II. Volume number density of the Au-rich precipitates and cavities of the current ternary samples and the previous binary Fe-Au samples. ${ }^{[19]}$ All the experiments are performed at a fixed temperature of $823 \mathrm{~K}\left(550{ }^{\circ} \mathrm{C}\right)$

\begin{tabular}{|c|c|c|c|c|c|c|c|c|}
\hline \multirow[b]{2}{*}{ Sample } & \multirow[b]{2}{*}{ Stress (MPa) } & \multirow[b]{2}{*}{ Lifetime (hours) } & \multicolumn{2}{|c|}{$d(\mu \mathrm{m})$} & \multicolumn{2}{|c|}{$n_{V}\left(\mu \mathrm{m}^{-3}\right)$} & \multicolumn{2}{|c|}{$f_{V}($ Percent $)$} \\
\hline & & & ppt & Cavity & ppt & Cavity & ppt & Cavity \\
\hline \multirow[t]{4}{*}{$\mathrm{Fe}-\mathrm{Au}$} & 60 & 641.7 & $0.76(4)$ & $1.5(1)$ & $1.7(1) \times 10^{-4}$ & $7.0(5) \times 10^{-5}$ & 0.098 & 0.64 \\
\hline & 80 & 375.7 & $0.63(4)$ & $1.50(6)$ & $1.3(1) \times 10^{-4}$ & $7.6(3) \times 10^{-5}$ & 0.24 & 0.76 \\
\hline & 100 & 209.9 & $0.67(3)$ & $0.86(2)$ & $9.3(6) \times 10^{-4}$ & $1.94(6) \times 10^{-4}$ & 0.35 & 0.24 \\
\hline & 117 & 57.2 & $0.63(3)$ & $0.85(4)$ & $1.11(7) \times 10^{-3}$ & $9.2(5) \times 10^{-5}$ & 0.14 & 0.11 \\
\hline \multirow[t]{3}{*}{$\mathrm{Fe}-\mathrm{Au}-\mathrm{W}$} & 180 & 141.6 & $0.27(9)$ & $0.7(1)$ & $1.1(4) \times 10^{-2}$ & $1.4(2) \times 10^{-3}$ & $0.032(7)$ & $0.10(2)$ \\
\hline & 200 & 97.4 & $0.44(5)$ & $0.8(2)$ & $3.3(5) \times 10^{-3}$ & $1.8(3) \times 10^{-3}$ & 0.03 (1) & $0.09(3)$ \\
\hline & 235 & 50.6 & $0.203(4)$ & $0.6(1)$ & $1.1(3) \times 10^{-2}$ & $1.9(1) \times 10^{-3}$ & $0.011(6)$ & $0.033(6)$ \\
\hline
\end{tabular}


grain boundaries, before they are transferred to the cavities by grain boundary diffusion. In the diffusion process of the supersaturated solute from the bulk to the creep cavities the volume diffusivity is the rate-controlling factor, while grain boundaries serve as fast diffusion paths. The 1D flux (from one side of the matrix) is estimated by ${ }^{[28]}$ :

$$
J_{X}=\frac{D_{X} \Delta x}{\Omega}\left(\frac{1}{\sqrt{\pi D_{X} t}}\right)=\frac{\Delta x}{\Omega} \sqrt{\frac{D_{X}}{\pi t}},
$$

where $\Delta x=x_{\infty}-x_{1}$ is the supersaturation of the solute, $D_{X}$ is the diffusivity of the solute element in the matrix phase, $\Omega$ is the atomic volume and $t$ is the time. Assuming that the solute that arrives at the free surface forms a layer with a fixed solute concentration $x_{p}$, the layer thickness $a$ follows from the mass balance $x_{p} \frac{\mathrm{d} a}{\mathrm{~d}_{t}}=\Omega J_{X}$. Starting from a homogeneous supersaturated matrix with $a(t=0)=0$ this results in a parabolic thickening of the precipitate layer:

$$
a(t)=\frac{\Omega}{x_{p}} \int_{0}^{t} J_{X}\left(a, t^{\prime}\right) \mathrm{d} t^{\prime}=\frac{2 \sqrt{D_{X} t}}{\sqrt{\pi}} \frac{\Delta x}{x_{p}} .
$$

When $\lambda$ is the creep cavity spacing at the grain boundary (oriented perpendicular to the stress) then a surface area $S_{0}=\lambda^{2}$ contributes to the cavity filling by solute transport from the bulk. For a surface area $S_{0}$ the total precipitation volume amounts to:

$$
V_{\text {diff }}(t)=a(t) S_{0}=\frac{2 S_{0} \sqrt{D_{X} t}}{\sqrt{\pi}} \frac{\Delta x}{x_{p}} .
$$

Experimentally, the total precipitation volume on one single side of the fracture surface with a surface area of $S_{0}$ can be estimated as:

$$
V_{\exp }=\frac{\pi}{6} S_{0} d^{3} n_{A}
$$

where $(\pi / 6) d^{3}$ corresponds to the average volume of the precipitates, $n_{A}$ is the areal number density.

The calculated and experimental results are shown in Figure 10. It is worth to note that the Au-rich precipitates are more or less uniformly distributed over the whole fracture surface, while the $\mathrm{W}$-rich precipitates are only distributed within the rectangular-shaped cavities. As shown in Figures 5(d) through (f), the areal number density of W-rich particles is only meaningful when the area of the rectangular-shaped cavity is considered (instead of the whole fracture surface area). Therefore, the values of $n_{A}$ for the $\mathrm{W}$-rich and Au-rich precipitates in Eq.[4] are studied in different areal units. As shown in Figure 10, the W-rich precipitates volume estimated from the experiments agrees well with the result calculated based on the 1D diffusion, indicating that the precipitation of the $\mathrm{W}$-rich phase is controlled locally by the volume diffusion of $\mathrm{W}$ atoms towards the cavity surface. The precipitation of the Au-rich phase, on the other hand, has a faster kinetics compared to the prediction by the $1 \mathrm{D}$ diffusion model, suggesting the

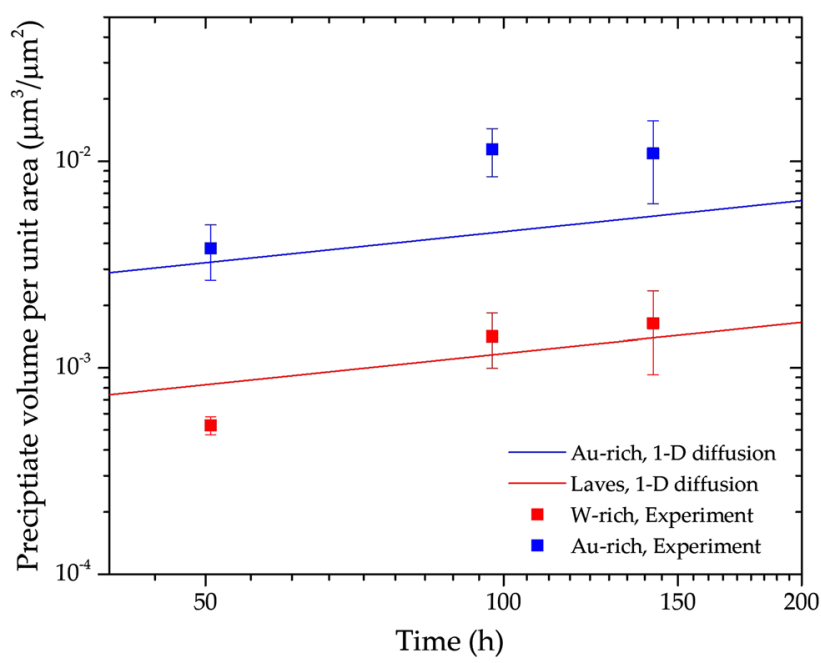

Fig. 10-Diffusion controlled precipitation volume as a function of time. The solid curves are calculated by $V_{\text {diff }}(t)=$ $(2 / \sqrt{\pi})\left(\Delta x / x_{p}\right) \sqrt{D_{X} t}$ and the scattered data points are calculated by $V_{\exp }=(\pi / 6) d^{3} n_{A}$. Note that the W-rich precipitate volume is estimated by assuming that the $\mathrm{W}$-rich precipitates are uniformly distributed over the creep cavity surface.

presence of faster pathways, in comparison to volume diffusion. In our previous study, ${ }^{[20]}$ an effective diffusivity, which is two orders of magnitude larger than the volume diffusivity was observed, owing to the formation of subgrains during creep. Since no evidence of subgrains was observed, the faster healing kinetics might be attributed by other defects, such as dislocations.

\section{CONCLUSIONS}

The autonomous healing of creep-induced grain boundary cavities by Au-rich and $\mathrm{W}$-rich precipitates in a Fe-3Au-4W (wt pct) ternary system have been studied. The ternary alloy, with two supersaturated healing solutes inside, serves as a model system to provide insight in the interplay between two separate healing agents. The creep tests were done at a high temperature of $823 \mathrm{~K}\left(550{ }^{\circ} \mathrm{C}\right)$ with different applied stresses. The creep properties of the ternary alloy are evaluated and compared with those of the previously studied $\mathrm{Fe}-\mathrm{Au}$ and $\mathrm{Fe}-\mathrm{W}$ binary systems. The microstructures of the creep-failed samples are studied in detail by electron microscopy to investigate the cavity filling behavior and the mass transfer of supersaturated solute to the defect sites. The main conclusions are as follows:

(1) Compared with the two binary Fe-Au and Fe-W systems, the ternary Fe-Au-W system shows the lowest steady-state strain rate and the longest creep lifetime. The Fe-Au-W alloy has similar creep rate-controlling mechanism as the $\mathrm{Fe}-\mathrm{W}$ alloy.

(2) During creep at a temperature of $823 \mathrm{~K}\left(550{ }^{\circ} \mathrm{C}\right)$, $\mathrm{Au}$-rich and $\mathrm{W}$-rich precipitates form predominantly on the free surface of the creep-induced cavities and thus heal the cavities. A filling ratio 
of $71 \mathrm{pct}$ is achieved for the for the lowest applied stress of $180 \mathrm{MPa}$.

(3) By investigating the fracture surfaces of the creep-failed samples, two types of precipitates are found: micron-sized Au-rich precipitates and nano-sized W-rich particles. The Au-rich precipitates show the capacity of fully filling the cavities, while the W-rich particles, which are distributed over the cavity surface, show only a limited degree of healing. The two types of precipitates show an apparent reluctance of coexistence when the lifetime is shorter than $100 \mathrm{~h}$.

(4) The healing mechanism of the Fe-Au-W system is as follows: due to the fast $\mathrm{Au}$ diffusivity, early-formed creep-induced cavities are filled by the Au-rich precipitates, which results in the formation of a zone that is depleted in Au. The cavities that form at a later stage in this Au-depleted zone can only be partially filled by $\mathrm{W}$-rich precipitates.

(5) Compared to the previous binary $\mathrm{Fe}-\mathrm{Au}$ and $\mathrm{Fe}-\mathrm{W}$ systems, the average sizes of the precipitates and the cavities in the ternary Fe-W-Au system are smaller, while their number densities are larger. This indicates that the precipitate-precipitate coalescence and the cavity-cavity linkage is limited.

(6) The Au-rich precipitation is controlled by a combination of volume diffusion and grain boundary diffusion of supersaturated $\mathrm{Au}$ solute, which is accelerated by matrix defects, such as dislocations. The $\mathrm{W}$-rich precipitation in the cavities is locally controlled by a $1 \mathrm{D}$ diffusion of solute $\mathrm{W}$, while the formation of W-rich Laves phase precipitates is suppressed on microscopic length scales.

\section{ACKNOWLEDGMENTS}

$\mathrm{Y}$. Fu acknowledges the financial support provided by China Scholarship Council (CSC).

\section{OPEN ACCESS}

This article is licensed under a Creative Commons Attribution 4.0 International License, which permits use, sharing, adaptation, distribution and reproduction in any medium or format, as long as you give appropriate credit to the original author(s) and the source, provide a link to the Creative Commons licence, and indicate if changes were made. The images or other third party material in this article are included in the article's Creative Commons licence, unless indicated otherwise in a credit line to the material. If material is not included in the article's Creative Commons licence and your intended use is not permitted by statutory regulation or exceeds the permitted use, you will need to obtain permission directly from the copyright holder. To view a copy of this licence, visit http://creat ivecommons.org/licenses/by/4.0/.

\section{ELECTRONIC SUPPLEMENTARY MATERIAL}

The online version of this article (https://doi.org/10. 1007/s11661-020-05862-6) contains supplementary material, which is available to authorized users.

\section{REFERENCES}

1. F.R.N. Nabarro and H.L. de Villiers: Physics of Creep and Creep-Resistant Alloys, CRC Press, Boca Raton, 2018.

2. K. Maruyama, K. Sawada, and J. Koike: ISIJ Int., 2001, vol. 41, pp. 641-53.

3. M. Taneike, F. Abe, and K. Sawada: Nature, 2003, vol. 424, pp. 294-96.

4. M.D. Hager, P. Greil, C. Leyens, S. van der Zwaag, and U.S. Schubert: Adv. Mater., 2010, vol. 22, pp. 5424-30.

5. B. Grabowski and C. Tasan: Self-Healing Materials, Springer International Publishing, Cham, 2016, pp. 387-407.

6. Niels. van Dijk and Sybrand. van der Zwaag: Adv. Mater. Interfaces, 2018, vol. 5, p. 1800226.

7. R.N. Lumley, A.J. Morton, and I.J. Polmear: Acta Mater., 2002, vol. 50, pp. 3597-608.

8. R. N. Lumley and I. J. Polmear, In Proceedings of the First International Conference on Self Healing Materials, (Noordwijk aan Zee 2007).

9. K. Laha, J. Kyono, S. Kishimoto, and N. Shinya: Scr. Mater., 2005, vol. 52, pp. 675-78.

10. K. Laha, J. Kyono, T. Sasaki, S. Kishimoto, and N. Shinya: Metall. Mater. Trans. A, 2005, vol. 36A, pp. 399-409.

11. N. Shinya, J. Kyono, and K. Laha: J. Intell. Mater. Syst. Struct., 2016, vol. 17, pp. 1127-33.

12. S.M. He, N.H. van Dijk, H. Schut, E.R. Peekstok, and S. van der Zwaag: Phys. Rev. B, 2010, vol. 81, p. 094103.

13. S. van der Zwaag and E. Brinkman: Self Healing Materials: Pioneering Research in the Netherlands, IOS Press, Amsterdam, 2015.

14. S. Zhang, J. Kohlbrecher, F.D. Tichelaar, G. Langelaan, E. Brück, S. van der Zwaag, and N.H. van Dijk: Acta Mater., 2013, vol. 61, pp. 7009-19.

15. S. Zhang, G. Langelaan, J.C. Brouwer, W.G. Sloof, E. Brück, S. van der Zwaag, and N.H. van Dijk: J. Alloys Comp., 2014, vol. 584, pp. 425-29.

16. S. Zhang, H. Fang, M.E. Gramsma, C. Kwakernaak, W.G. Sloof, F.D. Tichelaar, M. Kuzmina, M. Herbig, D. Raabe, E. Brück, S. van der Zwaag, and N.H. van Dijk: Metall. Mater. Trans. A, 2016, vol. 47A, pp. 4831-44.

17. S. Zhang, C. Kwakernaak, W. Sloof, E. Brück, S. van der Zwaag, and N.H. van Dijk: Adv. Eng. Mater., 2015, vol. 17, pp. 598-603.

18. H. Fang, N. Szymanski, C.D. Versteylen, P. Cloetens, C. Kwakernaak, W.G. Sloof, F.D. Tichelaar, S. Balachandran, M. Herbig, E. Brück, S. van der Zwaag, and N.H. van Dijk: Acta Mater., 2019, vol. 166, pp. 531-42.

19. H. Fang, C.D. Versteylen, S. Zhang, Y. Yang, P. Cloetens, D. Ngan-Tillard, E. Brück, S. van der Zwaag, and N.H. van Dijk: Acta Mater., 2016, vol. 121, pp. 352-64.

20. S. Zhang, C. Kwakernaak, F.D. Tichelaar, W.G. Sloof, M. Kuzmina, M. Herbig, D. Raabe, E. Brück, S. van der Zwaag, and N.H. van Dijk: Metall. Mater. Trans. A, 2015, vol. 46A, pp. $5656-70$.

21. S.M. He, P.N. Brandhoff, H. Schut, S. van der Zwaag, and N.H. van Dijk: J. Mater. Sci., 2013, vol. 48, pp. 6150-56.

22. S. Zhang, J. Cizek, Z. Yao, M. Oleksandr, X. Kong, C. Liu, N.H. van Dijk, and S. van der Zwaag: J. Alloys Comp., 2019, https://doi.org/10.1016/j.jallcom.2019.152765. 
23. C.D. Versteylen, M.H.F. Sluiter, and N.H. van Dijk: J. Mater. Sci., 2018, vol. 53, pp. 14758-73.

24. O.D. Sherby: Acta Metall., 1962, vol. 10, pp. 135-47.

25. J.S. Zhang: High Temperature Deformation and Fracture of Materials, Woodhead Publishing, Sawston, 2010.

26. C.D. Versteylen, N.H. van Dijk, and M.H.F. Sluiter: Phys. Rev. B, 2017, vol. 96, p. 094105.
27. G. Stechauner and E. Kozeschnik: J. Mater. Eng. Perform., 2014, vol. 23, pp. 1576-79.

28. C.D. Versteylen, N.K. Szymański, M.H.F. Sluiter, and N.H. van Dijk: Philos. Mag., 2018, vol. 98, pp. 864-77.

Publisher's Note Springer Nature remains neutral with regard to jurisdictional claims in published maps and institutional affiliations. 